\title{
POTENSI PERANCANGAN WEB RESPONSIVE SEBAGAI MEDIA KOMUNIKASI VISUAL
}

\author{
Dewi Immaniar ${ }^{1}$ \\ Iswahyudi $^{2}$ \\ Wahyu Setiono ${ }^{3}$ \\ Alumni STMIK Raharja Program Studi Magister Teknologi Informasi ${ }^{1}$, Mahasiswa STMIK \\ Raharja jurusan Teknik Informatika², Mahasiswa STMIK Raharja Jurusan Teknik \\ Informatika ${ }^{3}$ \\ Email: dewi.immaniar@raharja.info, iswahyudi@raharja.info,wahyu.setiono@raharja.info
}

Diterima : 17 Februari 2015/ Disetujui : 24 Februari 2015

\begin{abstract}
Currently the communication media very grown rapidly. The world was know new communication model, known as the internet. Internet is a global network that enables the establishment of communication and interaction across the globe. One very well-known form is a web-site. As the media dissemination of information through visual communication, web site is a potential and an outstanding job for visual communication designer. But sometimes a web site that has terpublis less display design principles that are executed in harmony. Rules of designing web sites less attention. Design a website in principle the same as visual communication design. Critical elements in the design of visual communication as typografi, illustration and photography are key design planning web-site display. In its design, the web is implemented using Bootstrap framework. Bootstrap itself is used as a means to create websites that can be integrated automatically when accessed on any device including PC, tablets and smartphones. In addition, the draft will be enhanced or supported by PHP, CSS, HTML, and SQL Server and design visual design with application of vector processing program and image processing program applications. Understanding of design principles and design rules are very helpful in designing web sites become more harmonious as a promotional medium of visual communication.
\end{abstract}

Keywords: Design, Visual Communication, Web, Design Principles

\begin{abstract}
ABSTRAK
Saat ini media komunikasi sangat berkembang dengan pesatnya.Dunia dilanda model komunikasi baru yang dikenal dengan internet.Internet merupakan salah satu jaringan global yang memungkinkan terjalinnya komunikasi dan interaksi di seluruh dunia.Salah satu bentuknya yang sangat terkenal adalah situs-web.Sebagai media penyebaran informasi melalui komunikasi visual, situs web merupakan potensi dan lapangan kerja yang luar biasa bagi desainer komunikasi visual. Namun terkadang situs web yang telah terpublis kurang menampilkan prinsip-prinsip desain yang tereksekusi dengan harmonis. Kaidah-kaidah perancangan situs-web kurang diperhatikan. Padahal untuk merancang situs web dalam prinsipnya sama dengan desain komunikasi visual. Unsur-unsur penting dalam desain komunikasi visual seperti typografi, illustrasi dan fotografi merupakan kunci perancangan desain tampilan situs-web.Dalam perancangannya, web yang diimplementasikan menggunakan framework Bootstrap. Bootstrap sendiri digunakan sebagai sarana untuk membuat tampilan website agar dapat terintegrasi secara otomatis saat diakses pada
\end{abstract}


perangkat apapun termasuk $P C$, tablet dan smartphone. Selain itu rancangan akan disempurnakan atau didukung dengan PHP, CSS, HTML, serta SQL Server dan perancangan design visual dengan aplikasi program pengolah vector maupun aplikasi program pengolah image. Pemahaman prinsip desain dan kaidah desain sangat membantu dalam merancang situs web menjadi lebih harmonis sebagai media promosi komunikasi visual.

Kata kunci: Desain, Komunikasi Visual, Web, Prinsip Design

\section{PENDAHULUAN}

\begin{tabular}{l}
\multicolumn{4}{c}{ Perkembangan teknologi yang } \\
terus meningkat dengan cepat dan \\
mengagumkan, mempengaruhi laju \\
kebutuhan manusia atas informasi, terlebih \\
disuatu organisasi atau perusahaan. \\
Internet merupakan salah satu jaringan \\
global yang memungkinkan terjalinnya \\
komunikasi dan interaksi di seluruh dunia. \\
Dibandingkan dengan belanja \\
konvensional, konsep e-commerce
\end{tabular} mempunyai banyak kemudahan dan kelebihan. Selain kemudahan transaksi juga dapat menghemat waktu. Website responsive dapat meningkatkan terjadinya transaksi pada bisnis. Berdasarkan perkembangan teknologi saat ini banyak pengakses internet dari kalangan pengguna tablet dan smartphone.

Internet menjadi media yang banyak di gunakan oleh berbagai kalangan untuk memenuhi kebutuhan informasi guna menunjang kebutuhan bisnis maupun study yang untuk menunjang aktivitas mereka. Hal ini terjadi karena pada dasarnya kebutuhan setiap individu sangatlah beraneka ragam, sehingga adanya kebutuhan inilah yang menimbulkan motif untuk menemukan informasi pada sebuah media yang paling dianggap tepat. Akibatnya muncul berbagai cara dan strategi untuk mendapatkan informasi tersebut. Dalam hal ini internet banyak digunakan karena menawarkan berbagai kemudahan untuk dapat mengakses berbagai referensi sesuai dengan kebutuhan.

Ulasan dari kompas.com bahkan menyatakan pengguna internet Pengguna Indonesia Nomor Enam Dunia. Berapa jumlah pengguna internet di Indonesia?
Menurut lembaga riset pasar e-Marketer, populasi netter Tanah Air mencapai 83,7 juta orang pada 2014. Angka yang berlaku untuk setiap orang yang mengakses internet setidaknya satu kali setiap bulan itu mendudukkan Indonesia di peringkat ke-6 di dunia dalam hal jumlah pengguna internet. Pada 2017, e-Marketer memperkirakan, jumlah netter Indonesia bakal mencapai 112 juta orang, mengalahkan Jepang pada peringkat ke-5, yang pertumbuhan jumlah pengguna internetnya lebih lamban. Secara keseluruhan, jumlah pengguna internet di seluruh dunia diproyeksikan bakal mencapai 3 miliar orang pada 2015. Tiga tahun setelahnya, pada 2018, diperkirakan sebanyak 3,6 miliar manusia di bumi bakal mengakses internet, setidaknya sekali tiap satu bulan. [14]
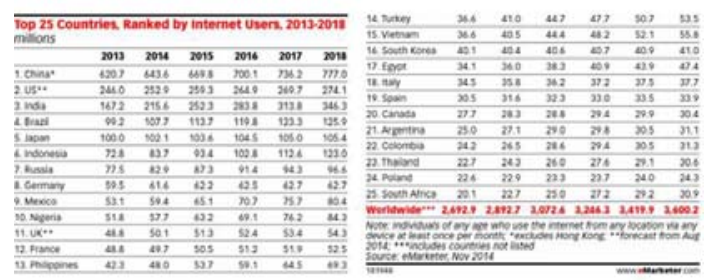

Gambar 1. Pengguna internetSumber dari http://tekno.kompas.com/read/2014/

Gambaran dari ulasan diatas menjelaskan Internet dalam era informasi telah menempatkan dirinya sebagai salah satu pusat informasi yang dapat diakses dari berbagai tempat tanpa dibatasi oleh ruang dan waktu. Pengguna internet semakin lama semakin meningkat dan internet menjadi peluang yang sangat besar. Terbukti dari Indonesia sendiri menduduki peringkat ke-6 di dunia dalam hal jumlah pengguna internet. Jumlah yang 
sangat besar dan juga peluang e-commerce yang besar. Potensi besar bagi pengusaha Indonesia untuk memanfaatkan web site sebagai komunikasi visual untuk $e$ commerce. China menempati tingkat pertama sebagai pengguna Internet, disusul oleh US, India lalu Brazil dan Jepang.

Bahkan William J.Mitchell ini menegaskan bagaimana internet bahkan merubah pola hidup seseorang, My Name is wjm@mit.edu (though I have many aliases), and I am an electronic. I hang out on the network. The keyboard is may café. Each morning I turn to some nearby machine -my modest personal computer at home, a more powerful workstasion in one of the offices or laboratories that I frequent, or laptop in a hotel room- log into electronic mail. I click on an icon to open an "inbox" filled with mesagges from round the world -replies to technical questions, queries for me to answer, drafts of papers, submissions of student work, appoinments, travel and meeting arrangements, bits of business, greetings, reminders, chit-chat, gossips, complaint, tips, jokes, flirtation...[10]

Informasi tentang berbagai hal ini sebetulnya dapat diperoleh dengan mudah di Internet dengan cara membaca berbagai referensi statistik yang ada \& dapat diakses secara cuma-cuma di Internet. Menurut Bambang Supradono, Komposisi traffic Web Indonesia yang berhasil dikumpulkan dari berbagai statistik yang ada dapat disimpulkan 60-70\% traffic Web Indonesia datangnya dari/ke komputer yang ada diIndonesia. Dari pernyataan diatas Tampak bahwa untuk saat ini potensi pasar Internet di Indonesia lebih banyak untuk kalangan Indonesia sendiri. [11]

Jadi Indonesia merupakan pengguna internet sekaligus pelaku bisnis yang jual beli nya dijalankan oleh kalangan Indonesia, dari sinipun terlihat peluang yang sangat besar jika bisa gointernational bukan hanya di indonesia. Internet kini telah menjadi pasar potensial di dunia, tercatat lebih dari 200 juta orang pengguna media ini.Dari data disebutkan bahwa 67 juta pengguna internet diantaranya berada di Amerika Serikat.

Bisnis internet dalam tahun-tahun terakhir meningkat luar biasa.Setelah hadirnya teknologi informasi-komunikasi internet, media ini telah menjadi secondwind bagi lajunya perahu bisnis komunikasi di dunia.Pemanfaatan internet untuk berbagai aktivitas usaha disebut dengan E-commerce. Kegiatan bisnis yang dilakukan secara online itu bisa meliputi pemasaran, promosi, public relation, transaksi, pembayaran, dan penjadwalan pengiriman barang, serta masih sangat terbuka kemungkinan inovasi-inovasi kegiatan bisnis online baru seiring dengan perkembangan teknologi e-commerce sendiri.

Website responsive dapat meningkatkan terjadinya transaksi pada bisnis toko online. Berdasarkan perkembangan teknologi saat ini banyak pengakses internet dari kalangan pengguna tablet dan smartphone. Penerapan teknologi melalui media tablet dan smartphone akan memberikan aksesibilitas dan fleksibilitas yang lebih, dalam melakukan transaksi maupun mendapatkan informasi sebuah toko online yang diinginkan. 

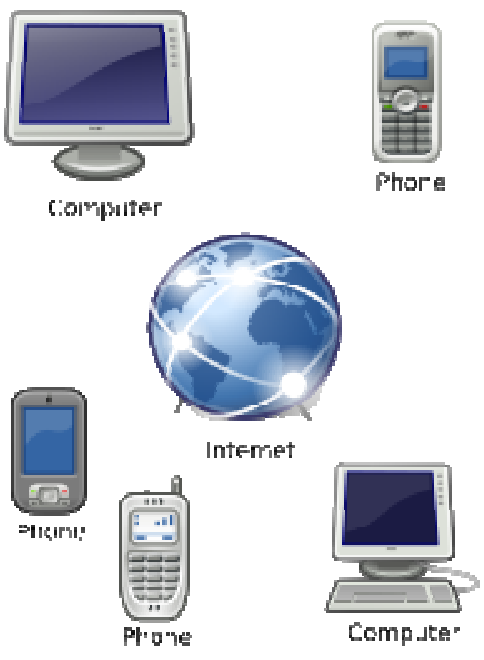

Gambar 2. Illustrasi Website Responsive

Dari gambar 2 website responsive dapat dilihat dari berbagai media tablet maupun komputer. Teknologi yang diaplikasikan akan memberikan kemudahan efisiensi penggunaan mendapatkan informasi maupun melakukan jual beli secara online. Web Responsive memerlukan komunikasi visual yang diatur sedemikian rupa baik layout maupun typografinya sehingga informasi yang disampaikan bisa maksimal.

Menurut Kalakota dan Whinston [8] dapat ditinjau dari perspektif berikut: a. Perspektif komunikasi, e- commerce adalah pengiriman barang, layanan, informasi atau pembayaran melalui jaringan komputer atau melalui peralatan elektronik lainnya. b. Perspektif proses bisnis, e-commerce adalah aplikasi dari teknologi yang menuju otomatisasi dari transaksi bisnis dan aliran kerja c. Perpektif layanan, e-commerce merupakan suatu alat yang memenuhi keinginan perusahaan, konsumen, dan manajemen untuk memangkas biaya layanan (service cost) ketika meningkatkan kualitas barang dan meningkatkan kecepatan layanan pengiriman d. Perpekstif online, $e$ commerce menyediakan kemampuan untuk membeli dan menjual barang atau informasi melalui internet dan sarana online lainnya.

Asmono Wikan

perkembangan internet yang sangat cepat disebabkan oleh karena (1) bersifat cepat, sesuatu terjadi sangat cepat dan informasipun mengalir secepat kilat melalui internet (2) berubah dengan cepat pula, internet kemarin berbeda dengan hari ini (3) tools baru bermunculan, seperti pengembangan software dan hardware yang pesat, serta muncul dari sumber nontradisional; (4) pemakai baru bermunculan dari mana-mana.

\section{PERMASALAHAN}

Web memang memiliki banyak keunggulan terlebih untuk promosi dan informasi. Namun diantara keunggulan itu, terkadang web yang terpublis ketika ditampilkan menggunakan media yang lain seperti tablet maupun smartphone tidak bisa tampil maksimal. Web yang digunakan sebagai media promosi komunikasi visual juga kurang menampilkan prinsip-prinsip desain yang tereksekusi dengan harmonis. Kaidahkaidah perancangan situs-web tidak berbeda jauh dengan kaidah-kaidah pokok desain komunikasi visual. Berikut ini disampaikan Prinsip-prinsip Dasar Perancangan:

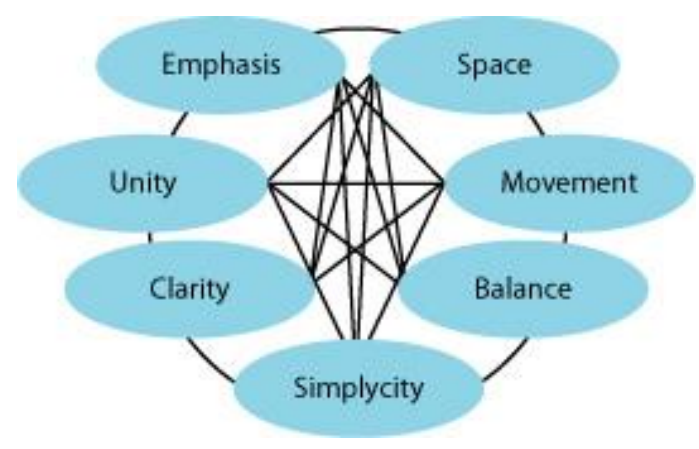

Gambar 3. Prinsip-prinsip Dasar Perancangan 
Dari gambar diatas, kita bisa lihat bahwa prinsip dasar perancangan saling terhubung satu sama lainnya hingga membentuk tarikan yang saling terkait. Desainer Komunikasi Visual bertanggung jawab atas pemecahan masalah komunikasi dalam menyampaikan informasi tersebut secara fungsional, elegan, proporsional, sederhana dan ekonomis, demikian halnya pada perancangan sebuah situs web.

\section{LITERATURE REVIEW}

Banyak penelitian yang sebelumnya dilakukan mengenai design komunikasi visual dan media promosi. Dalam upaya pengembangan design komunikasi visual dan media promosi ini perlu dilakukan studi pustaka sebagai salah satu dari penerapan metode penelitian yang akan dilakukan. Diantaranya adalah mengidentifikasikan kesenjangan (identify gaps), menghindari pembuatan ulang (reinventing the wheel), mengidentifikasikan metode yang pernah dilakukan, meneruskan penelitian sebelumnya, serta mengetahui orang lain yang spesialisasi dan area penelitiannya sama dibidang ini. Beberapa Literature review tersebut adalah sebagai berikut:

1. Penelitian ini dilakukan oleh Bing Bedjo Tanudjaja. Dosen Jurusan Desain Komunikasi Visual Fakultas Seni dan Desain Universitas Kristen Petra. Penelitian yang dilakukan dengan judul "Aplikasi Prinsip Gestalt Pada Media Desain Komunikasi Visual". Prinsip Gestalt yang diperkenalkan pada sekitar tahun 1920 oleh Max Wertheimer merupakan deskripsi secara umum untuk konsep yang membuat kesatuan dan berbagai kemungkinan dalam desain. Prinsip Gestalt dan Persepsi visual merupakan pengertian yang sangat membantu sebagai metode visual utama dari perkembangan strategi visual desain grafis serta desain komunikasi visual saat ini. Seorang desainer grafis dalam menata tampilan visual dan ruang komposisi untuk menciptakan sebuah rancangan yang efektif dan komunikatif, tentu memperhatikan tendensi dari perilaku manusia dalam melihat sebuah tampilan visual. Karakter, gaya hidup, dan kultur masyarakat di tiap Negara berbeda dan ini memungkinkan para desainer untuk bermain dalam lingkup yang satu ini dengan memanfaatkan situasi dan kondisi lingkungan. Membuat sebuah karya desain komunikasi visual yang cepat dilirik oleh publik barangkali tidaklah terlalu sulit, namun output visual yang unik menyentuh dan menggugah emosi publik adalah jenjang kreativitas yang berbeda.[12]

2. Penelitian ini dilakukan oleh Freddy H. Istanto. Penelitian yang dilakukan mengenai dekontruksi dengan judul "Dekonstruksi Dalam Desain Komunikasi Visual Sebuah Penjelajahan Kemungkinan Studi Kasus Desain Iklan Rokok AMild". Dosen Jurusan Desain Komunikasi Visual Fakultas Seni dan Desain Universitas Kristen Petra ini menyatakan Dekonstruksi hadir dengan latar-belakang postmodernisme yang berdasarkan pemikiran filsafat bahwa susunan pemikiran yang begitu terpadu, yang tersusun rapi, kini dipilahpilah sampai ke dasar-dasarnya. Kehadiran dekonstruksi dilihat sebagai bagian dari posmodernisme yang secara epistemologi atau filsafat pengetahuan, harus menerima suatu kenyataan bahwa manusia tidak boleh terpaku pada suatu sistim pemikiran yang begitu ketat dan kaku. Tulisan ini mencoba untuk mencari 
kemungkinan penerapan dekonstruksi pada disiplin Desain Komunikasi Visual utamanya dengan menghadirkan desain iklan rokok A-mild sebagai studi kasus. Ber-dekonstruksi kita belajar tentang kekayaan yang dimiliki Desain Komunikasi Visual, dimana unusr-unsur terkecilnya sekalipun atau elemen-elemen yang terpinggirkan dapat berpeluang untuk self-referensial dan sekaligus menjadi unsur integral Desain Komunikasi Visual.[5]

3. Penelitian ini dilakukan oleh Bagus Limandoko dengan judul "Desain Komunikasi Visual dan Perilaku Konsumen". Desain merupakan sebuah kata dengan banyak makna. Dalam konteks komunikasi visual, 'desain' sudah menjadi bagian dari tim dalam industri komunikasi. Dunia advertising, publikasi majalah dan suratkabar, pemasaran dan public relations, dan yang pasti 'desain' juga sudah menjadi salah satu aspek yang berpengaruh dalam membentuk perilaku suatu masyarakat dan perkembangan. Seorang desainer adalah orang yang punya kesempatan yang cukup untuk membuat suatu kreasi yang cukup berpengaruh untuk mengubah perilaku konsumen melalui karyanya, karena pada saatnya desain itu sendiri akan mengatakan kepada konsumen apa yang akan mereka peroleh bila memakai produk tertentu. Apa kata orang nanti? Apakah saya akan kelihatan muda, enerjik dan sportif kalausaya memakainya? Jadi pada dasarnya sebuah iklan adalah selalu mencoba untuk menjadi semacam pemenuhan kebutuhan tertentu manusia, misalnya rasa percaya diri tadi. Ini adalah kesempatan bagi desainer untuk mengangkat opiniopini baru lewat media yang tersedia yang akan berakhir menjadi perilaku masyarakat, walaupun itu hanya akan terjadi secara perlahan. [9]

4. Penelitian Ini Dilakukan Oleh Freddy H. Istanto Dosen Jurusan Desain Komunikasi Visual Fakultas Seni dan Desain Universitas Kristen Petra. Dengan judul "Potensi dan Kaidah Perancangan Situs-Web Sebagai Media Komunikasi Visual". Dunia dilanda model komunikasi baru yaitu internet. Salah satu bentuknya yang sangat terkenal adalah situsweb. Sebagai media penyebaran informasi melalui komunikasi visual, situs-web merupakan potensi dan lapangan kerja yang luar biasa bagi desainer komunikasi visual.Kaidah-kaidah perancangan situs-web tidak berbeda jauh dengan kaidah-kaidah pokok desain komunikasi visual. Elemen-elemen penting dalam desain komunikasi visual seperti typografi, ilustrasi, simbolisme dan fotografi merupakan kunci perancangan tampilan situs-web. Internet dikenal sebagai media yang sangat demokratis, kondisi ini sangat sesuai dengan proses demokrasi yang sedang tumbuh di Indonesia. Di Indonesia bahkan disebut sebagai media yang bebas birokrasi sehingga menjadi media yang murah, menyenangkan dan sebagai sebuah harga kebebasan. Peluang yang luarbiasa dari kemajuan teknologi komunikasiinformasi merupakan kesempatan yang sangat terbuka bagi para perancang desain komunikasi visual. Demikian pula sudah saatnya perguruan tinggi yang memiliki Jurusan Desain Komunikasi Visual segera mengambil sikap untuk menjawab tantangan dunia kerja yang semakin maju dengan pergerakan 
teknologi yang semakin canggih saja.[7]

5. Penelitian Ini Dilakukan Oleh Christine Suharto Cenadi Dengan Judul "Elemen-Elemen Dalam Desain Komunikasi Visual". Dosen Jurusan Desain Komunikasi Visual Fakultas Seni Dan Desain Universitas Kristen Petra. Dalam era globalisasi informasi dan teknologi seperti sekarang ini, Desain Komunikasi Visual berperan penting dan menjadi topik hangat yang tidak dapat terlepas dari kehidupan kita sehari-hari. Hampir setiap hari, kemanapun kita pergi, kita akan menjumpai bentukbentuk dari Desain Komunikasi Visual. Sayangnya, banyak diantara kita yang belum sadar akan tujuan dan manfaat dari Desain Komunikasi Visual itu sendiri. Tulisan ini akan membahas mengenai apa tujuan, manfaat, elemen dan lapangan kerja dari Desain Komunikasi Visual. Desain Komunikasi Visual merupakan suatu bidang baru yang sedang dan akan terus berkembang. Desain sendiri adalah suatu evolusi. Untuk sebagian orang, desain merupakan suatu perjalanan atau proses yang menyenangkan. Apa yang kita pikirkan dalam proses itu bercerita tentang diri kita dan proses kreatifitas. Selain itu, mengajarkan kita bagaimana sebuah desain yang berhasil lahir dari berbagai proses mencoba dan gagal (trial and error). Pada akhirnya, hasil dari desain itulah yang tentunya mendapatkan pengakuan, tetapi prosesnya yang membuat hasil itu menjadi berarti. Seperti kata Eugene Delacroix : "kita bekerja bukan hanya untuk berproduksi, tetapi untuk membuat waktu menjadi berharga.” [3]

6. Penelitian Ini Dilakukan Oleh Freddy H. Istanto dengan judul
"Gambar Sebagai Alat Komunikasi Visual" Bahasa gambar sangat dibutuhkan dalam dunia modern saat ini, dalam era komunikasi informasi ini peran gambar semakin besar saja. Gambar tidak saja penting bagi desainer, tetapi juga penting bagi ahli-ahli teknik, pendidikan, bisnis, sosial, politik dan industri. Tulisan ini akan merinci dari sejarah ditemukannya gambar sampai fungsi gambar sebagai alat komunikasi dalam dunia modern saat ini. Gagasan desain dalam pemikiran desainer dikomunikasikan dengan menggunakan gambar. Desain merupakan salah satu pendekatan dalam proses pemecahan masalah. Gambar adalah visualisasi dari proses desain, mulai tahap konsepsi hingga selesai. Presentasi grafis meng-efektif-kan evaluasi, sintesis, dan perumusan ide-ide. Gambar merupakan bagian yang integral dari desain, bukan hasil akhir suatu produk. Gaya hidup manusia juga selalu berubah dan bervariasi dan lingkungan hidup tempat kita tinggal juga berubah secara drastis. Informasi dan komunikasi yang sudah menjadi bagian dari gaya hidup jaman sekarang, mereka tidak begitu saja mengandalkan model-model tulisan dan lisan, dalam fungsinya yang spesifik gambar mengambil peran yang sangat luar biasa bagi perkembangan peradaban umat manusia. [6]

7. Penelitian yang dilakukan oleh Dewi Immaniar Desrianti dan Anita B. Wandanaya dengan judul "Penelitian Perancangan Media Katalog Sebagai Penunjang Informasi Dan Promosi Pada Cv.Zero Store". Pada masa sekarang ini seiring dengan ketatnya persaingan dalam dunia bisnis, pelayanan dan kualitas 
barang tidaklah cukup untuk bisa meningkatkan pendapatan dan menjaring konsumen yang loyal dan mau tidak mau hal ini membuat para pemilik perusahaan berpikir keras untuk menemukan cara agar bisa bertahan dan stabil dalam bisnisnya. Salah satu caranya adalah dengan menggunakan media komunikasi visual yang secara tidak langsung dapat diharapkan nilai efektifitasnya dalam mengkomunikasikan programprogram pemasaran produk. Oleh sebab itu, dibutuhkan sarana-sarana promosiyang lainnya seperti media Katalog yang diinginkan dalam target pemasaran yang telah diprogramkan. Untuk media Katalog yaitu suatu karya desain yang dikemas berupa booklet yang merupakan sebagai media yang dapat di jadikan asset perusahaan yang dapat digunakan untuk meningkatkan suatu image atau citra dari perusahaan untuk menjalin kerja sama dengan relasi perusahaan, lembaga dan instansi terkait lainnya. Selain itu perancangan yang baru ini diharapkan dapat menambah variant dari media promosi sehingga dapat membentuk image atau citra perusahaan sesuai dengan yang diinginkan. [4]

Dari tujuh literature review yang ada, telah banyak penelitian mengenai prinsip design, dekonstruksi, perilaku konsumen, design wen, elemen design, juga mengenai gambar visual, Disamping itu juga ada pembahasan mengenai corporate identity dan media promosi katalog. Namun dapat disimpulkan pula bahwa belum ada peneliti yang secara khusus membahas atau mengatasi masalah prinsip perancangan dan elemen yang terkait dengan design web sebagai media promosi.

\section{PEMBAHASAN}

Ernest Ackermann dan Karen Hartman dalam bukunya Internet and Web Essentials menyatakan komunikasi adalah penggunaan paling populer dari Internet." Communication is the most popular use of the Internet, with email topping the list of all the technologies used. Some of the types of communication technologies used also include email discussion groups, Usenet news, chat groups, and IRC. These are unique to networked computer environments and have come into wide popularity because of the Internet. Other technologies, including video and audio conferencing and Internet telephony, are also available on the Internet. They require more multimedia capabilities of computer systems and are more taxing ofnetwork resources than the others. They also are adaptations of other technologies to the Internet. Most of the technologies that are unique to the Internet require communication to be done in text-letters with some symbols and punctuation. Communicating effectively involves taking the time, except in informal communications, to use correct grammar, spelling, and punctuation and writing an appropriate message. When replying to a message include the pertinent parts of the message and use an appropriate and interesting subject header in any case". [1] Uraian diatas memberikan informasi bahwa teknologi internet dalam kaidahnya adalah untuk dipergunakan sebagai komunikasi yang dirancang melalui teknologi-teknologi. Internet sebagai media komunikasi yang pastinya memerlukan tampilan design sebagai interfacing atar komunikan.

Andoko berpendapat bahwa "The real internet is not technology, it's about people communicating, people offering and searching for information”. Tampilan atau produk dari sebuah internet adalah sebuah proses komunikasi yang 
disampaikan secara visual. Kerja seorang perancang atau Desainer Komunikasi Visual berkaitan dengan informasi dan proses komunikasinya untuk dibaca oleh orang atau sekumpulan orang, termasuk didalamnya adalah usaha untuk mempengaruhi orang atau sekumpulan orang dengan kerja tersebut [2].

Desainer komunikasi Visual bertanggung jawab atas pemecahan masalah komunikasi dalam menyampaikan informasi tersebut secara fungsional. Menurut Dewi Immaniar dalam diktatnya berpendapat Desain Grafis dapat didefinisikan sebagai aplikasi dari ketrampilan seni dan komunikasi untuk kebutuhan bisnis dan industri yang biasa disebut seni komersial. Dalam desain grafis, teks juga dianggap gambar karena merupakan hasil abstraksi simbol-simbol yang bisa dibunyikan.Desain grafis diterapkan dalam desain komunikasi dan fine art. Seperti jenis disain lainnya, disain grafis dapat merujuk kepada proses pembuatan, metoda merancang, produk yang dihasilkan (rancangan), atau pun disiplin ilmu yang digunakan (desain). Dengan informasi tersebut desain grafis berpengaruh menghasilkan bentuk media komunikasi yang eye catching demikian halnya pada perancangan sebuah situsweb.

Sebuah web dihadirkan dengan baik bukan hanya dari programmer, proses komunikasi sebuah kerja web-site menghadirkan produk komunikasi visual, sehingga tampilan situs web sangat ditentukan oleh perancang web-nya. Menurut John Maeda menyatakan bahwa sebaiknya seseorang bisa merangkap baik sebagai artis (designer) dan teknisi (programer) sekaligus. Jika demikian,tampilan pada web site adalah tampilan sebuah karya rancang desain komunikasi visual. Rancangan komunikasi visual situs web merupakan rancangan untuk media berkonunikasi virtual yang dikaitkan dengan teknologi. Sebuah design situs web harus dapet memenuhi dari fasilitas layanan kemudahan yang biasanya selalu ditawarkan oleh internet, design situs web jangan menampilkan sesuatu tampilan yang sulit dimengerti atau biasa disebut user friendly.

Inti dari perancangan design situs web tidaklah jauh design komunikasi visual. Perancangan media komunikasi visual terdapat prinsip-prinsip design dan elemen-elemen design. Prinsip perancangan design antara lain emphasis, space, unity, movement, clarity, balance, simplycity. Elemen elemen yang digunakan untuk membuat situs web seperti tipografi, simbolisme, ilustrasi dan fotografi.

Dalam kasus ini web yang dibuat digunakan sebagai media promosi jual beli (e commerce) dengan nama Perusahaan Eben Haezer Net yang dapat diakses secara online dari link http://www.vivasusi.vv.si/bootshop/

Web yang diimplementasikan menggunakan framework Bootstrap. Bootstrap sendiri digunakan sebagai sarana untuk membuat tampilan website agar dapat terintegrasi secara otomatis saat diakses pada perangkat apapun termasuk PC, tablet dan smartphone. Selain itu rancangan akan disempurnakan atau didukung dengan PHP, CSS, HTML, serta SQL Server dan perancangan design visual dengan aplikasi program pengolah vector maupun aplikasi program pengolah image. Pemahaman prinsip desain dan kaidah desain sangat membantu dalam merancang situs web menjadi lebih harmonis sebagai media promosi komunikasi visual.

\section{IMPLEMENTASI}

Perencanaan Visual (Konsep Visual). Eben Haezer Net ingin memberikan kesan mudah mencari informasi produk bagi para pelanggannya. Dan ingin memberikan informasi jelas kepada pengunjung website karena telah menimbang lay out website, penggunaan huruf dan pemilihan warna. Setiap bagian yang disampaikan dalam tampilan setiap halaman oleh penulis adalah merupakan 
media informasi dan promosi mengenai produk-produk pada toko online Eben Haezer Net. Disamping itu Eben Haezer Net juga ingin menampilkan image sebagai toko online yang terpercaya dengan menampilkan logo baru untuk website ini.Ini merupakan bentuk salah satu bukti keseriusan Eben Haezer Net terhadap bisnis toko online.Dan juga menguatkan citra Eben Haezer Net sebagai toko online dengan pelayanan dan kredibelitas tinggi.

Pengarahan Visualisasi

Visualisasi yang terdapat dalam rancangan media diantaranya: (a). Warna, Pewarnaan rancangan tampilan halamanhalaman website responsive ini lebih cenderung menggunakan warna-warna identik dengan perusahaan yaitu dengan dominasi warna biru dan merah.Tampilan Ikon atau Tab menggunakan pewarnaan hitam, sementara untuk Tab kategori menggunakan warna putih.Sementara pewarnaan huruf menggunakan warna hitam dan putih, warna biru digunakan sebagai warna link halaman; (b). Jenis Huruf, Jenis huruf yang digunakan pada rancangan media website ini adalah Calibri, Times New Roman dan SansSarif; (c). Tata Letak (layout), tata letak unsurunsur tampilan media website cenderung menggunakan tampilan list; (d). Gaya Penampilan Grafis, gaya penampilan rancangan website menggunakan fasilitas bootstrape dimana bahasa tersebut mendukung untuk website yang ditujukan untuk para pengguna smartphone, tablet maupun dekstop berbagai ukuran layar; (e). Model Atau Produk Yang Ditampilkan, produk dalam rancangan website ini adalah smartphone, tablet dan aksesorisnya.

\section{Proses Desain (Designing)}

Pada bagian ini ditunjukkan berbagai alternatif pengemangan desain yang meliputi :

1. Lay out kasar

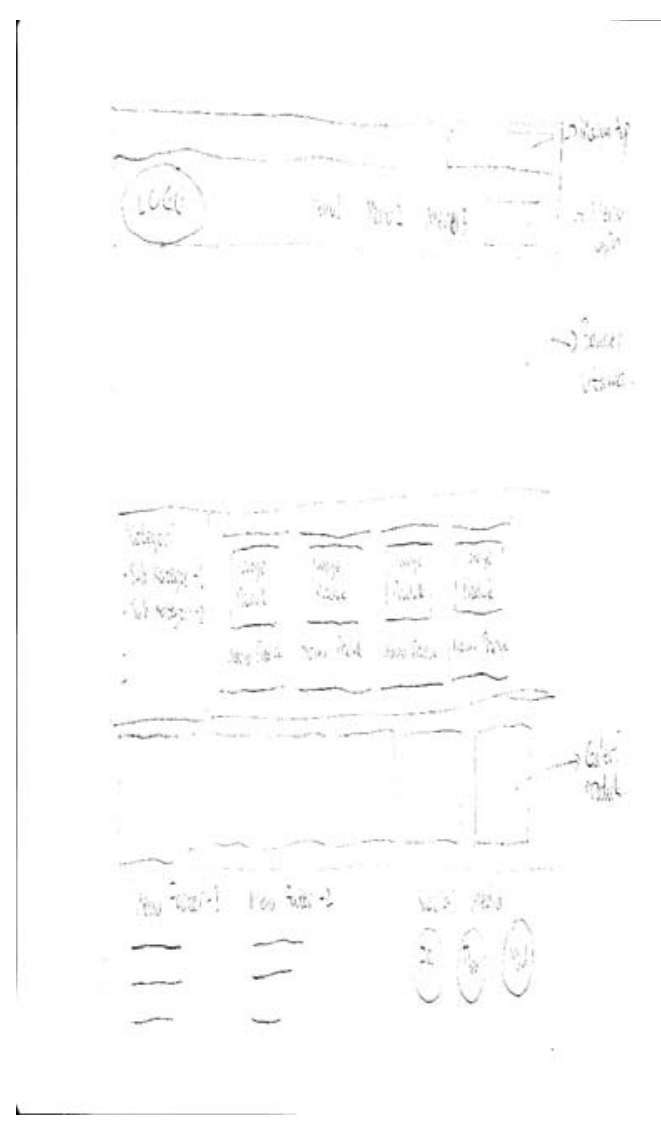

Gambar 4 Layout kasar tampilan dekstop

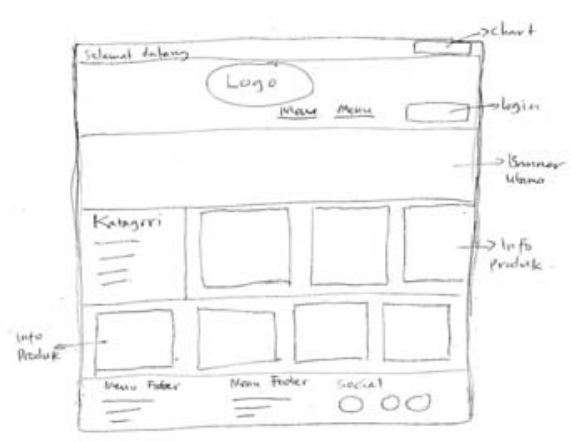

Gambar 5.layout kasar tampilan tablet 


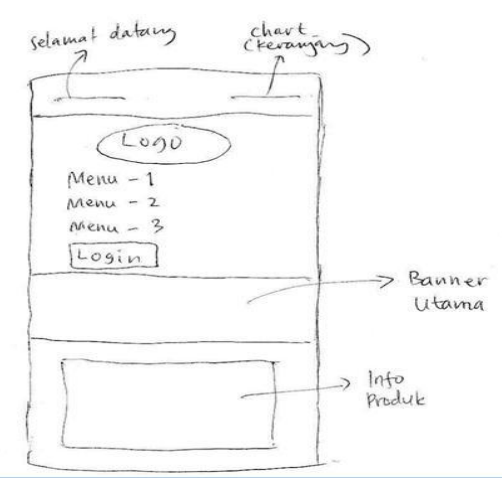

Gambar 6.layout kasar smartphone /mobile top

2. Layout Komprehensif

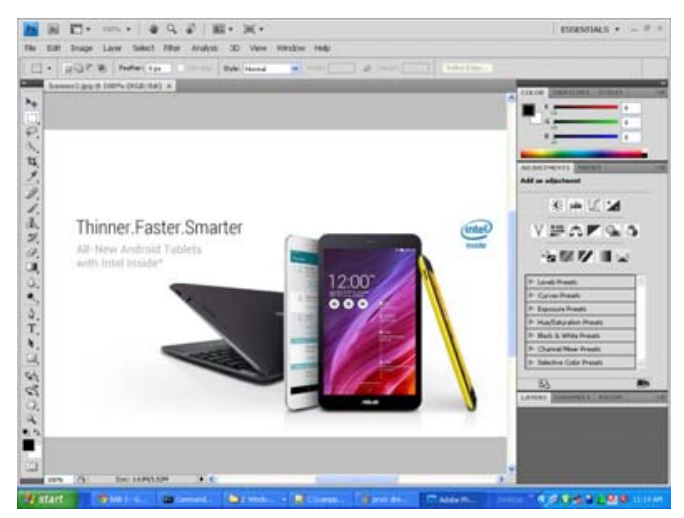

Gambar 7.layout kompreshensif photoshop

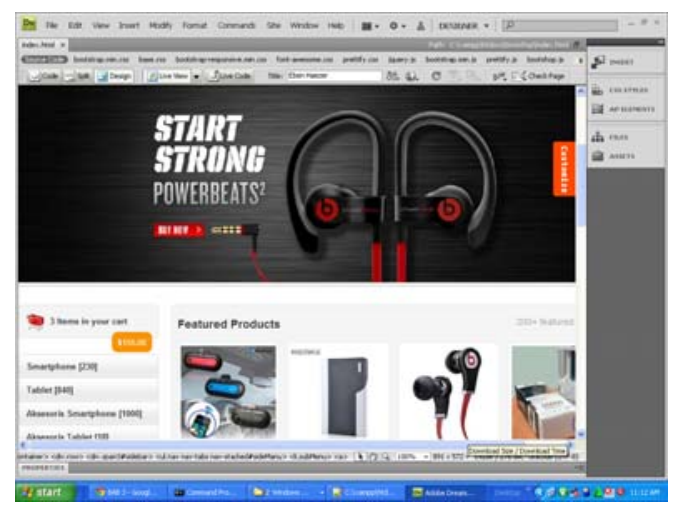

Gambar 8.layout kompreshensif dreamweaver

3. Final Art Work

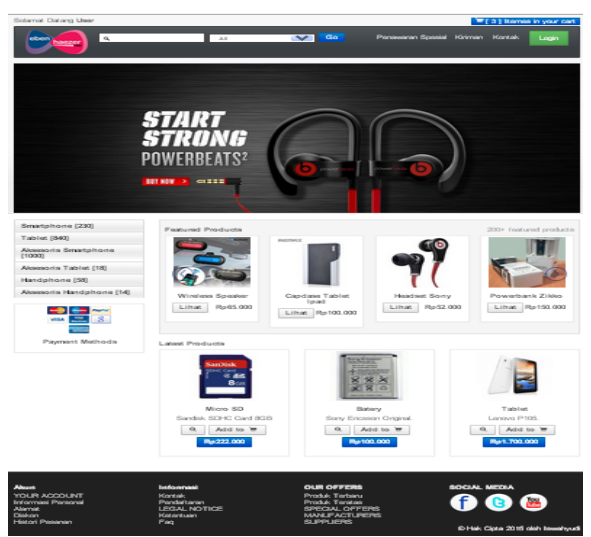

Gambar 9. Web desktop final view

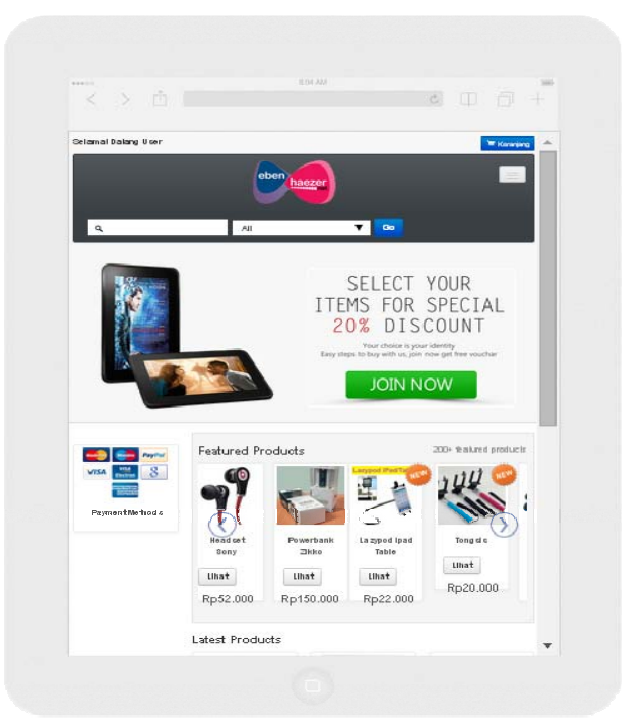

Gambar 10.web tablet final view

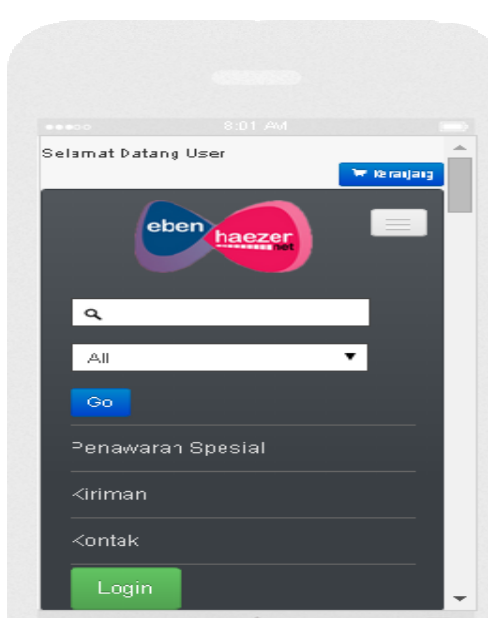


Gambar 11.web mobile final view

\section{KESIMPULAN}

Internet dalam era informasi telah menempatkan dirinya sebagai salah satu pusat informasi yang dapat diakses dari berbagai tempat tanpa dibatasi oleh ruang dan waktu.Pengguna internet semakin lama semakin meningkat dan internet menjadi peluang yang sangat besar.Terbukti dari Indonesia sendiri menduduki peringkat ke-6 di dunia dalam hal jumlah pengguna internet.Jumlah yang sangat besar dan juga peluang e-commerce yang besar.Potensi besar bagi pengusaha Indonesia untuk memanfaatkan web site sebagai komunikasi visual untuk ecommerce.

Website responsive dapat meningkatkan terjadinya transaksi pada bisnis toko online. Berdasarkan perkembangan teknologi saat ini banyak pengakses internet dari kalangan pengguna tablet dan smartphone. Penerapan teknologi melalui media tablet dan smartphone akan memberikan aksesibilitas dan fleksibilitas yang lebih, dalam melakukan transaksi maupun mendapatkan informasi sebuah toko online yang diinginkan

Inti dari perancangan design situs web tidaklah jauh design komunikasi visual. Perancangan media komunikasi visual terdapat prinsip-prinsip design dan elemen-elemen design. Prinsip perancangan design antara lain emphasis, space, unity, movement, clarity, balance, simplycity. Elemen elemen yang digunakan untuk membuat situs web seperti tipografi, simbolisme, ilustrasi dan fotografi. Dari implementasi web eben haezer dirancangan dari proses design analisa media, pengarahan visualisasi sampai Proses Desain (Designing) sehingga web yang aplikasikan sesuai dengan perancangan design dengan Prinsip perancangan design.

\section{DAFTAR PUSTAKA}

[1] Ackermann, Ernest and Karen Hartman, "Internet and Web Essentials". Franklin, Beedle and Associates, Incorporated, Wilsonville. 2000

[2] Andoko, Andrey, "Internet mengubah Cara berbisnis", Makalah Seminar Sukses Berbisnis di Era Internet, 22 Maret 2000

[3] Cenadi ,Christine Suharto. "Elemen-elemen dalam Desain Komunikasi Visual". Universitas Kristen Petra. Januari 2009

[4] Immaniar, Dewi. Anita B. Wandanaya dan Asih S. "Perancangan Media Katalog sebagai Penunjang Informasi dan Promosi Pada CV.Zero Store". CCIT Journal. Tangerang. Vol. 7 No.2. 2014

[5] Istanto , Freddy H. "Dekonstruksi Dalam Desain Komunikasi Visual Sebuah Penjelajahan Kemungkinan Studi Kasus Desain Iklan Rokok A-Mild". Fakultas Seni dan Desain Universitas Kristen Petra. , Januari 2003

[6] Istanto, Freddy H. "Gambar sebagai alat komunikasi visual". Universitas Kristen Petra.2003

[7] Istanto, Freddy H. "Potensi Dan Kaidah Perancangan Situs-Web Sebagai Media Komunikasi Visual". Universitas Kristen Petra.2003

[8] Kalakota dan Whinston. "Definisikan e-commerce dari beberapa perspektif". 2007

[9] Limandoko, Bagus. "Desain Komunikasi Visual Dan Perilaku Konsumen". Universitas Kristen Petra. Juli 2000

[10] Mitchell, William J. "City of Bits: Space, Place and infobahn", MIT Press, Massachusetts. 2007 
[11] Supradono, Bambang. "Strategi Pemasaran lewat Internet (Cybermarketing)". $\quad$ Fakultas Teknik Universitas Muhammadiyah, Semarang .2005

[12] Tanudjaja, Bing Bedjo. "Aplikasi Prinsip Gestalt pada Media Desain Komunikasi Visual". Universitas Kristen Petra. Januari 2005

[13] Wikan, Asmono. "Miliaran dolar ditebar pasarpun diincar". Cakram Komunikasi. April 2000

[14] Yusuf, Oik. "Pengguna Internet Indonesia Nomor Enam Dunia". Diakses pada Senin 24 November 2014 dari: http://tekno.kompas.com/read/2014/ 11/24/07430087/pengguna.internet.i ndonesia.nomor.ena m.dunia 